\title{
O BOOM NO INVESTIMENTO EM ESTUFAS NA REGIÃO DE TRÁS-OS-MONTES E ALTO DOURO, 1990-95: O PERFIL DO "NOVO" EMPRESÁRIO AGRÍCOLA
}

\author{
Chris Gerry* \\ José Vaz Caldas** \\ Timothy Koehnen**ok
}

Este trabalho apresenta os resultados preliminares dum projecto de investigação em curso, sobre o boom no investimento em agricultura de estufas na região de Trás-os-Montes e Alto Douro, durante o período de 1990-95. Na primeira fase deste projecto, a cujos resultados este artigo se refere, realizámos uma análise detalhada de 100 planos de melhoria submetidos à delegação regional do Instituto Financeiro de Apoio ao Desenvolvimento da Agricultura e Pescas (IFADAP), em Vila Real, no âmbito dos regulamentos comunitários $n^{a} 797 / 85$ e 2328/91, com vista ao financiamento de projectos, exclusiva ou parcialmente, orientados à agricultura em estufas. $O$ objectivo principal deste trabalho é o de definir o perfil do agricultor-tipo investidor em agricultura de estufas. As conclusões a que chegámos nesta fase inicial sugerem que o sucesso ou insucesso de tais investimentos não podem ser unicamente explicados por razões internas à própria exploração. Na análise da evolução do tecido empresarial rural, o papel, às vezes determinante, desempenhado pela fileira na qual a empresa vem a integrar-se, deveria receber a devida atenção. $A$ influência, quer positiva, quer negativa, de actores económicos

* Professor Associado Convidado do Departamento de Economia e Sociologia da Universidade de Trás-os-Montes e Alto Douro (UTAD).

** Professor Auxiliar do Departamento de Economia e Sociologia da Universidade de Trás-os-Montes e Alto Douro (UTAD) e Docente do Instituto Universitário de Desenvolvimento e Promoção Social - Pólo de Viseu da Universidade Católica Portuguesa.

*** Professor Associado Convidado do Departamento de Economia e Sociologia da Universidade de Trás-os-Montes e Alto Douro (UTAD). 
e institucionais-chave no processo de investimento, tais como o IFADAP, os construtores de estufas, os fornecedores de inputs agrícolas, os retalhistas/grossistas que escoam a produção realizada, e os projectistas, deve ser também cuidadosamente analisada, de forma a que iniciativas futuras de apoio a este tipo de investimento possam ter o máximo sucesso.

\section{INTRODUÇÃO}

Mesmo os mais ocasionais observadores da paisagem agrária do nordeste de Portugal puderam assistir, ao longo dos últimos dez anos, ao desenvolvimento de um novo tipo de agricultura na região, a agricultura em estufas (Pereira, 1996). Durante a primeira parte dos anos noventa, investimentos significativos começaram a ser feitos em estufas na região de Trás-os-Montes e Alto Douro nas áreas da horticultura, floricultura e plantas ornamentais. O seu aparecimento, ainda que tardio ${ }^{1}$, sugere tanto uma nova dinâmica empresarial como uma mudança de atitudes e prioridades. Claramente, estes investimentos proporcionam aos agricultores a possibilidade de obter um rendimento adicional, através da satisfação duma procura de bens "fora da estação", tanto nos mercados interno como externo, e uma maior estabilidade de rendimentos ao longo do ano agrícola. A sua implementação contou com o apoio de fundos comunitários geridos pelo IFADAP. ${ }^{2}$

No entanto, as consequências quanto à natureza, amplitude, significado e sustentabilidade desta nova tendência estão ainda por analisar. Este trabalho surge como um primeiro estudo sobre a viabilidade económica da agricultura de estufas numa região periférica, que sofre de problemas de interioridade e marginalização, que têm até agora limitado o seu desenvolvimento económico e social. Como "retardatário" na agricultura em estufas, Trás-os-Montes e Alto Douro, ao invés de tentar recuperar o atraso com que começou, pode procurar usufruir da vantagem de poder aprender com os sucessos e os erros de outras regiões, desde que as exigências de uma produção cada vez mais globalizada e de um mercado cada vez mais competitivo o permitam (Aldonado, 1992).

O objectivo principal deste estudo é o definir o perfil do agricultor-tipo investidor em estufas. A primeira etapa desta investigação envolveu a análise de 100 planos de melhoria, submetidos pelos agricultores ao departamento regional do IFADAP, em Vila Real. A estrutura adoptada neste trabalho é a seguinte: na secção 2 analisam-se os dados recolhidos; a secção 3 apresenta as características gerais do investidor-tipo, definidoras do seu perfil; na secção 4 faz-se uma análise mais detalhada do comportamento do investidor-tipo, mediante a definição de 3 tipologias; na secção 5 apresentam-se algumas reflexões sobre o seu perfil. Finalmente, na secção 6 são levantadas algumas 
questões que deverão ser objecto de futura investigação. Com as considerações feitas nesta secção pretende-se que, em fases posteriores desta investigação, se definam critérios que levem à eleição de uma amostra de agricultores, com vista a uma análise mais detalhada sobre o perfil do investidor em estufas na região de Trás-os-Montes e Alto Douro. Estes critérios possibilitariam avaliar do impacto e da sustentabilidade dos investimentos realizados $\mathrm{e}$, até certo ponto, identificar as variáveis preponderantes - quer limitadoras, quer potenciadoras ${ }^{3}$ - do desenvolvimento de uma "cultura empresarial" entre os pequenos e médios agricultores da região transmontana.

\section{ANÁLISE DOS DADOS RECOLHIDOS}

A definição do perfil do agricultor-tipo investidor em agricultura de estufas exige informação numerosa e diversa. No estudo realizado os dados foram recolhidos da seguinte forma:

- Análise de 100 das 141 propostas de investimento (planos de melhoria), apresentadas para financiamento na Delegação Regional de Trás-os-Montes e Alto Douro do IFADAP, em Vila Real, no período 1990-95, no âmbito do programa de "Melhoria da Eficácia das Estruturas Agrícolas", com base nos regulamentos comunitários n. ${ }^{\text {os }} 797 / 85$ e 2328/91;

- Estudos de viabilidade do IFADAP sobre as referidas propostas;

- Documentação anexa aos processos (contratos de venda da produção, estimativas sobre custos de produção, contratos de arrendamento).

Tanto a informação recolhida nos planos de melhoria, como a obtida nas apreciações feitas pelo IFADAP sobre os mesmos e documentação anexa sofre de limitações que são analisadas neste estudo e que devem ser levadas em conta em trabalhos futuros. As mais importantes são: (a) a fiabilidade dos dados recolhidos; (b) a adequação dos dados disponíveis; e (c) o problema da "autoria" dos planos de melhoria.

No que respeita à fiabilidade dos dados recolhidos, para além das imprecisões inerentes a qualquer processo de inquirição, é visível que alguns dos candidatos podem ter fornecido informações menos "precisas", de forma a poderem maximizar o subsídio a receber. Outros podem ter sido influenciados por consultores formais ou informais, levando-os a prestar informação que não reflecte necessariamente a realidade da exploração agrícola em questão. 
É também de referir a inadequação habitual entre os objectivos técnicos implícitos nos formulários do organismo financiador (ou seja selecção, avaliação e acompanhamento) e os requeridos por uma análise socioeconómica mais profunda (nomeadamente, informação reveladora da estratégia e performance da empresa agrícola e do investidor). Os planos de melhoria podem reflectir uma realidade socioeconómica e uma estratégia de investimento bastante mais complexa do que os pressupostos convencionais expressam - tanto quanto à unidade de análise "adequada", a empresa, como à correspondente racionalidade económica, por exemplo, a do agregado familiar. Embora o IFADÁP dê preferência especial à informação necessária à avaliação quantificada da viabilidade dos projectos apresentados, é de uma importância inquestionável à perfilização socioeconómica dos investidores, pretendida pelo presente estudo, aproveitar - embora indirectamente - a riqueza da informação qualitativa neles contida.

O problema da "autoria" dos planos de melhoria é a última das insuficiências dos dados oficiais a examinar. Pela análise dos projectos apresentados, é-nos possível perceber que a maioria deles não foi elaborada pelo agricultor, antes por técnicos e consultores, vulgarmente conhecidos como projectistas. Na realidade, em muitos casos, os planos de melhoria por eles elaborados reproduzem "informação-tipo", que se destina a assegurar a sua aprovação sob determinadas circunstâncias de oferta de fundos, em vez de reflectirem directamente os planos futuros da exploração do potencial beneficiário.

Não obstante estas reservas quanto aos dados disponíveis, estes constituem um bom ponto de partida para a definição do perfil do investidor-tipo e a caracterização do boom da agricultura em estufas em Trás-os-Montes e Alto Douro.

\section{CARACTERÍSTICAS GERAIS DO INVESTIDOR EM ESTUFAS}

Nesta seç̧ão pretendemos definir o perfil do agricultor-tipo que investiu em estufas no período de 1990-95, apresentando inicialmente características gerais inerentes ao investimento, ao agricultor e à exploração, as quais permitem posteriormente sintetizar o perfil genérico do investidor.

\subsection{Análise das características}

A análise destas características assenta na apreciação dos seguintes indicadores: 
- Cronologia do investimento

- Dimensão do investimento

- Vendas e retorno do investimento

- Sexo, idade e nível educacional

- Natureza da propriedade agrária

- Autoria do plano de melhoria

\section{a. Cronologia do investimento}

De 1987 a 1995, o IFADAP-Vila Real aprovou 141 planos de melhoria em estufas, conforme consta do Quadro 1. Estas decisões foram repartidas de forma bastante desigual ao longo do período em análise. Em 1991, o IFADAP autorizou subsídios para 20 planos de melhoria com uma componente em agricultura em estufas no âmbito do programa de "Melhoria da Eficácia das Estruturas Agrícolas", um número idêntico ao existente no período de 1987-1990. Mas o boom estava ainda para chegar. Até 1993 o número de pedidos de financiamento permaneceu relativamente constante.

\section{Quadro 1}

CRONOLOGIA DOS PLANOS DE MELHORIA EM AGRICULTURA DE ESTUFAS APROVADOS PELO IFADAP, TRÁS-OS-MONTES

E ALTO DOURO: 1987-1995

\begin{tabular}{|c|c|r|r|r|r|r|r|}
\hline \multirow{2}{*}{ Ano } & \multicolumn{2}{|c|}{ Homens } & \multicolumn{2}{c|}{ Mulheres } & Total da amostra & \multicolumn{2}{c|}{ Total } \\
\cline { 2 - 8 } & $\mathbf{N}^{\circ}$ & \multicolumn{1}{c|}{$\%$} & $\mathbf{N}^{\circ}$ & \multicolumn{1}{c|}{$\%$} & $\mathbf{N}^{\circ}$ & \multicolumn{1}{c|}{$\mathbf{N}^{\circ}$} & \multicolumn{1}{c|}{$\%$} \\
\hline 1987 & & & & & & 2 & 1,4 \\
\hline 1988 & & & & & & 5 & 3,5 \\
\hline 1989 & & & & & & 7 & 5,0 \\
\hline 1990 & 2 & 3,5 & 2 & 4,7 & 4 & 4 & 2,8 \\
\hline 1991 & 8 & 14,1 & 7 & 16,3 & 15 & 20 & 14,2 \\
\hline 1992 & 10 & 17,5 & 2 & 4,7 & 12 & 17 & 12,1 \\
\hline 1993 & 11 & 19,3 & 6 & 13,9 & 17 & 23 & 16,3 \\
\hline 1994 & 18 & 31,6 & 21 & 48,8 & 39 & 49 & 34,8 \\
\hline 1995 & 8 & 14,0 & 5 & 10,6 & 13 & 14 & 9,9 \\
\hline Total & 57 & 100,0 & 43 & 100,0 & 100 & 141 & 100,0 \\
\hline
\end{tabular}

No entanto, em 1993-1994 foram aprovados subsídios para 72 planos de melhoria, ou seja, cerca de metade dos aprovados para o período de 1987-1995. Só no ano de 1994 foi aprovado mais de um terço dos projectos apresentados, correspondentes a cerca de 500000 contos. Após 1994, o número de pedidos de solicitados desceu significativamente. 
A análise do padrão espacial do investimento permite-nos avaliar de forma mais concreta a localização do boom de 1990-95 (Quadro 2). Assim, é de referir que os escassos projectos existentes no início daquele período se concentraram fundamentalmente no eixo Chaves - Vila Real - Lamego. Nos anos seguintes o padrão inicial consolidou-se, especializando-se o concelho de Chaves em floricultura, respondendo à procura destes produtos no mercado espanhol, e a zona de Lamego em horticultura.

\section{Quadro 2}

LOCALIZAÇÃO DOS PLANOS DE MELHORIA EM AGRICULTURA DE ESTUFAS APROVADOS PELO IFADAP, TRÁS-OS-MONTES

E ALTO DOURO: 1987-1995

\begin{tabular}{|l|c|c|c|c|c|c|c|c|c|cr|}
\hline ÁREA & 1987 & 1988 & 1989 & 1990 & 1991 & 1992 & 1993 & 1994 & 1995 & TOTAL (\%) \\
\hline Chaves & 1 & 1 & 1 & 1 & 5 & 6 & 11 & 18 & 5 & 49 & $(35)$ \\
\hline $\begin{array}{l}\text { Vila Pouca de } \\
\text { Aguiar }\end{array}$ & & & & & 2 & 3 & & 3 & 3 & 11 & $(8)$ \\
\hline Vila Real & 1 & 1 & 3 & 1 & 2 & 2 & 3 & 9 & 3 & 25 & $(18)$ \\
\hline Mirandela & & 1 & & & 3 & 2 & 2 & 8 & & 16 & $(11)$ \\
\hline Lamego & & 1 & 3 & 2 & 6 & 4 & 7 & 8 & 3 & 34 & $(24)$ \\
\hline Bragança & & 1 & 1 & & 2 & & & 2 & & 6 & $(4)$ \\
\hline $\begin{array}{l}\text { Trás-os-Montes } \\
\text { E Alto Douro }\end{array}$ & 2 & 5 & 8 & 4 & 20 & 17 & 23 & 48 & 14 & 141 & $(100)$ \\
\hline
\end{tabular}

\section{b. Dimensão do investimento}

Desde o início do período em análise, o número e o valor médio dos investimentos projectados aumentaram substancialmente. Como ressalta do Quadro 3, o seu valor no período de 1990-95 foi de cerca de 10500 contos. Em 1993, apesar deste valor ter descido, o aumento significativo no número de projectos apresentados permitiu que o montante total investido seguisse a tendência de crescimento dos anos anteriores. No ano de 1994 o investimento total e médio atingiram os seus valores máximos, respectivamente de 493000 e 12600 contos, aproximadamente, tendo o masculino sido ligeiramente superior ao feminino ${ }^{4}$. 


\section{Quadro 3 \\ INVESTIMENTO TOTAL E MÉDIO DOS PLANOS DE MELHORIA EM AGRICULTURA DE ESTUFAS APROVADOS PELO IFADAP, TRÁS-OS-MONTES E ALTO DOURO: 1990-1995}

\begin{tabular}{|c|c|c|c|c|c|c|c|}
\hline \multirow{2}{*}{ Ano } & \multirow{2}{*}{$\begin{array}{c}\mathrm{N}^{\circ} \text { de } \\
\text { Projectos } \\
\text { Melhoria }\end{array}$} & \multirow{2}{*}{$\begin{array}{c}\text { Investi- } \\
\text { mento total } \\
\text { (contos) }\end{array}$} & \multirow{2}{*}{$\begin{array}{c}\text { Investi- } \\
\text { mento médio } \\
\text { (contos) }\end{array}$} & \multicolumn{2}{|c|}{$\begin{array}{c}\text { Investimento médio } \\
\text { (contos) }\end{array}$} & \multirow{2}{*}{$\begin{array}{l}\text { Peso no va- } \\
\text { lor do in- } \\
\text { vestimento } \\
\text { das mulhe- } \\
\text { res no dos } \\
\text { homens }\end{array}$} & \multirow{2}{*}{$\begin{array}{c}\text { Investi- } \\
\text { mento } \\
\text { Total } \\
(\%)\end{array}$} \\
\hline & & & & Homens & Mulheres & & \\
\hline 1990 & 4 & 20810 & 5202,5 & 5107 & 5298 & 104 & 2,0 \\
\hline 1991 & 15 & 130435 & 8695,7 & 9660 & 7594 & 79 & 12,4 \\
\hline 1992 & 12 & 129565 & 10797,1 & 10990 & 9832 & 89 & 12,3 \\
\hline 1993 & 17 & 141229 & 8307,6 & 8378 & 8178 & 98 & 13,4 \\
\hline 1994 & 39 & 492767 & 12635,1 & 13862 & 11583 & 84 & 46,8 \\
\hline 1995 & 13 & 137880 & 10606,1 & 11849 & 8617 & 73 & 13,1 \\
\hline Total & 100 & 1053022 & $10526,9\left(^{*}\right)$ & $11120(i)$ & $9740\left(\frac{i}{+}\right)$ & 88 & 100,0 \\
\hline
\end{tabular}

(*) Coeficiente de variação igual a 0,61 .

$(\dagger)$ Coeficiente de variação igual a 0,66 .

(†) Coeficiente de variação igual a 0,50 .

É ainda de salientar que os montantes investidos raramente ultrapassam os 15000 contos e que é nos finais do período que os projectos de maior envergadura são aprovados, como se pode ver pelo Quadro 4.

\section{Quadro 4}

NÍVEL DO INVESTIMENTO MÉDIO DOS PLANOS DE MELHORIA EM AGRICULTURA DE ESTUFAS APROVADOS PELO IFADAP, TRÁS-OS-MONTES E ALTO DOURO: 1990-1995

\begin{tabular}{|c|r|r|r|r|r|r|r|r|r|r|r|r|r|}
\hline $\begin{array}{c}\text { Valor do } \\
\text { Investimento } \\
\begin{array}{c}\text { Médio } \\
\text { (contos) }\end{array}\end{array}$ & \multicolumn{2}{|c|}{1990} & \multicolumn{2}{|c|}{1991} & \multicolumn{2}{|c|}{1992} & \multicolumn{2}{|c|}{1993} & \multicolumn{2}{|c|}{1994} & \multicolumn{2}{|c|}{1995} & \multirow{2}{*}{ Total } \\
\cline { 2 - 16 } & $\mathbf{N}^{0}$ & $\%$ & $\mathbf{N}^{\circ}$ & $\%$ & $\mathbf{N}^{\circ}$ & $\%$ & $\mathbf{N}^{\circ}$ & $\%$ & $\mathbf{N}^{\circ}$ & $\%$ & $\mathbf{N}^{\circ}$ & $\%$ & $\mathbf{N}^{0}$ e \% \\
\hline$<5000$ & 2 & $(50,0)$ & 6 & $(40,0)$ & 1 & $(8,3)$ & 4 & $(23,5)$ & 4 & $(10,3)$ & 2 & $(15,4)$ & 19 \\
\hline $5001-10000$ & 2 & $(50,0)$ & 5 & $(33,3)$ & 4 & $(33,3)$ & 6 & $(35,3)$ & 12 & $(30,8)$ & 4 & $(30,8)$ & 33 \\
\hline $10001-15000$ & 0 & & 2 & $(13,3)$ & 6 & $(50,0)$ & 6 & $(35,3)$ & 12 & $(30,8)$ & 4 & $(30,8)$ & 30 \\
\hline $15001-20000$ & 0 & & 1 & $(6,7)$ & 0 & & 1 & $(5,9)$ & 6 & $(15,4)$ & 3 & $(23,1)$ & 11 \\
\hline $20001-30000$ & 0 & & 1 & $(6,7)$ & 1 & $(8,3)$ & 0 & & 5 & $(12,8)$ & 0 & & 7 \\
\hline Total (\%) & 4 & $(100,0)$ & 15 & $(100,0)$ & 12 & $(100,0)$ & 17 & $(100,0)$ & 39 & $(100,0)$ & 13 & $(100,0)$ & 100 \\
\hline
\end{tabular}




\section{c. Vendas e retorno do investimento}

$\mathrm{Na}$ esmagadora maioria dos casos, os valores das vendas apresentados não reflectem qualquer experiência empresarial passada, uma vez que a agricultura em estufas é uma actividade nova na exploração, podendo mesmo constituir a primeira iniciativa empresarial do investidor. Assim, estes valores traduzem expectativas futuras, ou seja, valores esperados.

O total das vendas esperadas médias, para o período foi de 6210 contos $^{5}$, aparece com variações não muito significativas. Na venda de produtos provenientes, exclusivamente, da agricultura em estufas, os agricultores esperam obter um montante de 4440 contos, em média, correspondente a, aproximadamente, $72 \%$ do valor das vendas totais.

O retorno médio bruto do investimento ${ }^{6}$ foi de cerca de $37 \%$, mas com valores muito variáveis (coeficiente de variação de 0,96 ). Se excluirmos os 33 casos em que menos de dois terços das vendas são provenientes da produção em estufas (com um retorno de cerca de 44\%), o referido retorno desce para $33 \%$ (coeficiente de variação de 0,69 ). No entanto, uma vez que aproximadamente metade do investimento projectado é financiado pelo IFADAP, o retorno médio bruto do investimento real é o dobro do acima indicado.

\section{d. Sexo, idade e nível educacional}

Um dos problemas estruturais da agricultura portuguesa é o envelhecimento da população agrária. Contudo, o investidor em estufas é um jovem agricultor. A sua idade média é de 31 anos, sendo em média as mulheres um ano mais novas que os homens. Como mostra o Quadro 5, mais de $80 \%$ dos investidores tinham 35 anos ou menos na altura em que os projectos foram submetidos ao IFADAP (somente $4 \%$ dos planos de melhoria analisados pertencem a agricultores com mais de 40 anos). $O$ facto de a União Europeia subsidiar, através dos seus regulamentos n. ${ }^{\text {os }} 797 / 85$ e 2385/91, preferencialmente planos de melhoria de agricultores com menos de 40 anos, de forma a combater o continuado processo de desertificação demográfica em áreas rurais mais desfavorecidas, pode explicar esta constatação. Contudo, algum cuidado deve ser posto nesta análise, dado que, nos pedidos solicitados ao IFADAP, os jovens agricultores podem ter servido de "intermediários" de agricultores mais velhos a eles ligados por grau de parentesco, reflexo de uma estratégia mais familiar do que individual. 


\section{Quadro 5}

PLANOS DE MELHORIA EM AGRICULTURA DE ESTUFAS APROVADOS PELO IFADAP CONSIDERANDO O SEXO E A IDADE DOS INVESTIDORES, TRÁS-OS-MONTES E ALTO DOURO: 1990-1995

\begin{tabular}{|l|c|c|c|c|c|}
\hline \multicolumn{1}{|c|}{ Idade } & $\begin{array}{c}\mathbf{N}^{\circ} \mathbf{e} \% \text { de } \\
\text { Investidores }\end{array}$ & $\begin{array}{c}\text { Homens } \\
\left(\mathbf{N}^{\circ}\right)\end{array}$ & $\begin{array}{c}\text { Homens } \\
(\%)\end{array}$ & $\begin{array}{c}\text { Mulheres } \\
\left(\mathbf{N}^{\circ}\right)\end{array}$ & $\begin{array}{c}\text { Mulheres } \\
(\boldsymbol{\%})\end{array}$ \\
\hline 20 & 5 & 2 & 3,5 & 3 & 7,0 \\
\hline $21-25$ & 25 & 16 & 28,1 & 9 & 20,9 \\
\hline $26-30$ & 23 & 13 & 22,8 & 10 & 23,3 \\
\hline $31-35$ & 12 & 10 & 17,5 & 13 & 30,2 \\
\hline $36-40$ & 8 & 7 & 12,3 & 5 & 11,6 \\
\hline $41-50$ & 3 & 6 & 10,5 & 2 & 4,7 \\
\hline$>50$ & 1 & 2 & 3,5 & 1 & 2,3 \\
\hline Desconhecida & 1 & 1 & 1,8 & 0 & 0 \\
\hline Total & 100 & 57 & 100,0 & 43 & 100,0 \\
\hline
\end{tabular}

O baixo nível de instrução é outro dos problemas estruturais de relevo na agricultura portuguesa, que se verifica também no caso dos investidores em estufas (Quadro 6). Dos 81 casos para os quais havia informação disponível, cerca de metade tem o $6^{\circ}$ ano de escolaridade ou menos (com maior predominância do sector masculino), e só $25 \%$ dispõe de uma formação superior ao $9^{\circ}$ ano. Destes, unicamente $5 \%$ possuem um curso superior.

Embora a idade média dos homens não seja muito diferente da das mulheres (31,5 e 30,5 respectivamente), estas dispõem de um nível educacional superior ao daqueles. Esta constatação pode ser em parte explicada pela existência na nossa amostra de um grande número de mulheres jovens e com idade inferior à média, a par do recente aumento no número de anos de escolaridade obrigatória e das melhores oportunidades que o número adicional de anos de escolaridade lhes proporciona. 


\section{Quadro 6}

PLANOS DE MELHORIA EM AGRICULTURA DE ESTUFAS

APROVADOS PELO IFADAP, CONSIDERANDO O SEXO E O

NÍVEL EDUCACIONAL DOS INVESTIDORES, TRÁS-OS-MONTES E ALTO DOURO: 1990-1995

\begin{tabular}{|l|c|c|c|c|c|}
\hline \multirow{2}{*}{ Educação } & \multicolumn{2}{|c|}{ Investidores - Homens } & \multicolumn{2}{c|}{ Investidores - Mulheres } & $\begin{array}{c}\text { Investidores - } \\
\text { Total }\end{array}$ \\
\cline { 2 - 6 } & $\mathbf{N}^{\circ}$ & $\%$ & $\mathbf{N}^{\circ}$ & $\%$ & $\mathbf{N}^{\circ} \mathbf{e} \%$ \\
\hline $4^{\circ}$ ano & 12 & $(27,9)$ & 9 & $(23,7)$ & 21 \\
\hline $5^{\circ}-6^{\circ}$ ano & 14 & $(32,6)$ & 8 & $(21,1)$ & 22 \\
\hline $7^{\circ}-9^{\circ}$ ano & 6 & $(14,0)$ & 14 & $(36,8)$ & 20 \\
\hline $10^{\circ}-12^{\circ}$ ano & 8 & $(18,6)$ & 6 & $(15,8)$ & 14 \\
\hline Superior & 3 & $(7,0)$ & 1 & $(2,6)$ & 4 \\
\hline Subtotal & 43 & $(100,0)$ & 38 & $(100,0)$ & 81 \\
\hline Sem resposta & 14 & & 5 & & 19 \\
\hline Total & 57 & & 43 & & 100 \\
\hline
\end{tabular}

\section{e. Natureza da propriedade agrária}

A estrutura fundiária do investidor merece também a nossa atenção. Da análise dos planos de melhoria podemos concluir que os investidores são pequenos e médios agricultores, com uma área média de 3,5 hectares. Destes, $27 \%$ eram proprietários da exploração, $66 \%$ arrendatários e $7 \%$ situavam-se em ambas as categorias.

As razões pelas quais os investidores preferem arrendar a terra, a utilizarem a sua própria exploração, para realizarem os seus os projectos de estufas, não é para nós neste momento muito clara. Para tentarmos perceber as razões deste fenómeno há necessidade de proceder a investigação adicional.

A resposta a questões, como "será que a terra arrendada é de um familiar próximo do investidor, ou não?", permite-nos ponderar da importância da ocorrência de externalidades positivas, tais como a instalação de electricidade ou a captação de águas, na decisão de arrendar e a quem. Por exemplo, quando existe um laço de parentesco próximo entre o arrendatário e o senhorio, é de presumir que ficam na família, no termo do projecto, as benfeitorias realizadas, o que facilita a celebração de contratos de arrendamento entre estas partes. 


\section{f. Autoria dos planos de melhoria}

É de salientar que a expansão deste tipo de projectos se deve, não só ao trabalho de extensão e divulgação realizado pelos técnicos de IFADAP e das Zonas Agrárias, mas também à intervenção activa e empenhada - embora não sempre 'formal' ou directa - de projectistas ou consultores privados que, em $75 \%$ dos casos analisados, prepararam o plano apresentado pelo investidor em estufas.

\section{2. $O$ perfil genérico}

Da análise acima realizada podemos concluir que o investidor em estufas é um jovem agricultor ou agricultora (de cerca de trinta anos), com um nível educacional baixo - mais de $50 \%$ só têm o $6^{\circ}$ ano de escolaridade ou menos. É um pequeno/médio agricultor (área média de 3,5 ha) que arrenda normalmente a terra onde pretende desenvolver a sua actividade produtiva nas áreas da fruticultura, horticultura e plantas ornamentais. A sua exploração situa-se, em geral, no eixo Vila Real - Chaves - Lamego, e o seu investimento médio no período foi de 10500 contos, em média, a que correspondem taxas previsionais de retorno de $75 \%$ e $37 \%$, conforme se considere ou não os subsídios ao investimento como proveitos.

\section{DIFERENCIAÇÃO DOS INVESTIDORES EM ESTUFAS: TRÊS TIPOLOGIAS}

Ainda que a análise acima realizada permita definir o perfil do investidor-tipo, não possibilita contudo avaliar da sustentabilidade destas iniciativas empresariais e não oferece uma base de apoio completa para melhorar, no futuro, o aconselhamento, selecção e acompanhamento a realizar pelos organismos ligados ao Ministério da Agricultura, de forma a que se apliquem políticas adequadas ao sector. Há, assim, necessidade de proceder a um estudo mais detalhado sobre o comportamento do investidor-tipo. Para o efeito, procedeu-se à desagregação (tipificação) e análise da amostra recolhiḍa, definindo três tipologias de acordo com as seguintes variáveis:

- Dimensão do investimento realizado;

- Grau de especialização/diversificação produtiva do investidor;

- Grau de experiência empresarial do investidor. 
Embora estas não sejam as únicas tipologias passíveis de definição, elas constituem, no entanto, o ponto de partida para uma análise empírica posterior mais aprofundada sobre as performances dos investidores em estufas.

\subsection{Uma primeira tipologia: a dimensão do investimento realizado}

Como é quase convencional neste tipo de análise, a primeira tipologia refere-se à dimensão do investimento a realizar pelo agricultor. Na definição de pequeno, médio e grande investidor, tivemos em conta informação tanto de natureza qualitativa como quantitativa. Após analisarmos toda a informação recolhida para diferentes intervalos de classes e, dado que as frequências observadas seguem uma distribuição normal ${ }^{7}$, optámos por definir os pequenos investidores como aqueles que investem menos de 5000 contos, os médios como os que investem entre 5000 e 15000 contos, e os grandes como investidores que mobilizam mais de 15000 contos.

Os médios investidores constituem quase dois terços da nossa amostra, sendo as outras duas categorias de idêntica dimensão. Os pequenos são relativamente mais idosos e os maiores mais jovens, com predominância dos homens. Os médios são também jovens agricultores, sendo neste grupo o número de mulheres investidoras muito aproximado do dos homens.

Relativamente ao grau de instrução, a análise dos planos permite-nos concluir que o nível de escolaridade é baixo no caso dos pequenos e médios investidores (não mais que o $6^{\circ}$ ano), característica do tecido empresarial transmontano, em particular, e português, em geral. Contudo, os investidores de maior dimensão distinguem-se dos anteriores, por possuírem um nível médio educacional marcadamente acima do nono ano de escolaridade.

Os investimentos realizados nos arredores de Vila Real reflectem a distribuição geral entre pequenos, médios e grandes investimentos. Em contraste, os investimentos realizados na zona de Lamego são preferencialmente de média dimensão e, na área de Mirandela, predominantemente grandes.

$O$ arrendamento da terra para a realização do investimento foi muito mais frequente no caso dos médios investidores, tendo muito dos pequenos e grandes investidores utilizado as suas próprias explorações para desenvolverem os seus projectos.

$O$ retorno do investimento é maior para os pequenos investidores $(65 \% \mathrm{em}$ média), quando comparado com o dos outros dois grupos (33\% e $21 \%$ para médios e grandes, respectivamente). Salienta-se ainda que, no primeiro grupo, o investimento em projectos exclusivamente virados para agricultura em 
estufas é considerado mais rentável que o dos projectos mistos, embora com retornos muito variáveis.

Metade dos projectos apresentados por pequenos investidores, e $75 \%$ nos dois outros casos, foram preparados por projectistas. Esta constatação coloca-nos as seguintes questões: (1) será que os pequenos investidores são mais avessos ao risco ou dispõem de mais habilitações para preparar projectos de estufas? (2) ou será que os projectistas têm uma clara e activa preferência por projectos de maior envergadura (3) ou é simplesmente porque os maiores investidores, conscientes dos riscos consideráveis que acompanham a realização de investimentos, mesmo os subsidiados, recorrem mais ao trabalho de especialistas? A este conjunto de questões apenas é possível responder através de uma análise dos projectos a posteriori, confrontando o previsto com o efectivo.

\subsection{A tipologia segundo o grau de especialização da produção}

Pela leitura dos planos de melhoria foi possível concluir que o objectivo de parte dos agricultores é a especialização, enquanto outros viram na diversificação uma forma de sucesso futuro; $38 \%$ destes planos foram identificados como projectos mistos, ou seja, planos que combinam produções e/ou actividades da agricultura em estufas com outras culturas e respectivas actividades. No entanto, em certos casos, foi difícil concluir, para cada uma das rubricas de investimento incluídas nos referidos planos, quais eram, exclusiva e claramente, investimento em estufas e as que correspondiam a outras produções/actividades.

Nestas circunstâncias, decidiu-se medir o grau de especialização da produção em estufas de cada um dos investidores, pelo critério das vendas previsionais de cada produção. Assim, os agricultores foram classificados como "especialistas" ou "diversificadores", consoante a maior ou menor concentração numa ou mais culturas do valor das vendas previsionais relativamente ao valor das vendas totais.

Neste contexto, definiram-se as seguintes categorias de planos de melhoria:

- Planos especializados, virados quase exclusivamente para a floricultura em estufas;

- Planos diversificadores, caracterizados por uma combinação de floricultura e/ou horticultura em estufas, horticultura ao ar livre e outras produções;

- Planos 'minimalistas', nos quais a componente estufas na actividade da exploração é mínima. 
Pela leitura dos Quadros 7 e 8, verifica-se que 50 dos 100 planos de melhoria pertencem a investidores especializados em floricultura (sobretudo cravos, rosas e gerberas), 39 dos quais apresentaram projectos para a realização exclusiva de agricultura em estufas. Da sua análise ressalta também o peso dos agricultores para os quais a agricultura em estufas é apenas um complemento, de reduzida importância, à agricultura tradicional (22), que chamámos investidores minimalistas. Os restantes casos foram agrupados num conjunto que denominámos de investidores-diversificadores, pois a realização do investimento implica uma maior diversidade cultural na sua produção.

\section{Quadro 7}

\section{CLASSIFICAÇÃO DOS INVESTIDORES COM BASE NAS VENDAS PREVISIONAIS, TRÁS-OS-MONTES E ALTO DOURO: 1990-95}

\begin{tabular}{|c|c|c|c|c|c|c|}
\hline $\begin{array}{c}\text { Valores das } \\
\text { Vendas } \\
\text { esperadas } \\
\text { (contos) }\end{array}$ & $\begin{array}{c}\text { A. Estufas- } \\
\text {-foricultura } \\
\text { quase ex- } \\
\text { clusivamente }\end{array}$ & $\begin{array}{c}\text { B.Estufas } \\
\text { floricultura } \\
\text { horticultura }\end{array}$ & $\begin{array}{c}\text { C.Estufas } \\
\text { floricultura< } \\
\text { horticultura }\end{array}$ & $\begin{array}{c}\text { D. Combi- } \\
\text { nação estu- } \\
\text { fas/outras } \\
\text { culturas }\end{array}$ & $\begin{array}{c}\text { E.Estufas } \\
\text { componente } \\
\text { mínima }\end{array}$ & Total \\
\hline$<1000$ & 0 & 0 & 0 & 0 & 1 & 1 \\
\hline $1001-2500$ & 2 & 1 & 2 & 1 & 1 & 7 \\
\hline $2501-5000$ & 15 & 8 & 2 & 4 & 9 & 38 \\
\hline $5001-10000$ & 26 & 3 & 2 & 3 & 8 & 42 \\
\hline $10001-20000$ & 7 & 0 & 0 & 1 & 3 & 11 \\
\hline$>20000$ & 0 & 0 & 0 & 1 & 0 & 1 \\
\hline Total & 50 & 12 & 6 & 10 & 22 & 100 \\
\hline
\end{tabular}

Metade dos planos da "agricultura especializada" foram propostos por mulheres, enquanto que a proporção de empresárias "diversificadoras" e "minimalistas" foi apenas de um terço.

\section{Quadro 8}

VENDAS PREVISIONAIS E O GRAU DE ESPECIALIZAÇÃO DO INVESTIDOR EM ESTUFAS, TRÁS-OS-MONTES E ALTO DOURO: 1990-95.

\begin{tabular}{|l|c|c|c|c|}
\hline & Especialistas & Diversificadores & Minimalistas & Total \\
\hline $\mathrm{N}^{\circ}$ de Investidores & $50(50)$ & $28(28)$ & $22(22)$ & $100(100)$ \\
\hline $\mathrm{N}^{\circ}$ de Homens & $24(42)$ & $19(33)$ & $14(25)$ & $57(100)$ \\
$\mathrm{N}^{\circ}$ de Mulheres & $26(60)$ & $9(21)$ & $8(19)$ & $43(100)$
\end{tabular}

Idade média: Homens

28,4

30 ,

Mulheres 29,5


Os minimalistas são tendencialmente mais idosos que os outros investidores, sendo nítida também a diferença de idades entre investidores masculinos e femininos nesta categoria $(32$ e 38 anos de idade, respectivamente), ao contrário do que acontece nas outras duas, cujo perfil etário dos homens e mulheres é idêntico.

No caso dos especialistas e dos minimalistas, o investimento subsidiado teve o seu ponto alto em 1994, enquanto o dos diversificadores foi mais uniforme durante o período em análise. Em termos espaciais, existem clusters de investimento por especialistas e diversificadores não só no eixo Chaves -Vila Real, mas também nas áreas de Lamego e Mirandela. O investimento dos minimalistas caracteriza-se por uma maior dispersão espacial, ainda que uma parte significativa deles se situe à volta de Vila Real e de Mirandela.

Em termos gerais, o valor do investimento médio é semelhante em todas as categorias acima definidas, sendo, no entanto, ligeiramente menos vultuoso no caso dos diversificadores ${ }^{8}$.

Por sua vez, o valor das vendas médias esperadas totais é também muito semelhante para os três tipos de agricultores aqui estudados, conforme se pode ver no Quadro 9, embora a taxa de retorno dos especialistas e dos diversificadores (29\%) seja ligeiramente inferior à dos minimalistas (37\%).

\section{Quadro 9 \\ VENDAS PREVISIONAIS MÉDIAS POR GRAU DE ESPECIALIZAÇÃO DO INVESTIDOR EM ESTUFAS, TRÁS-OS-MONTES E ALTO DOURO: 1990-95}

\begin{tabular}{|l|c|c|c|}
\hline Tipo de Investidor & $\begin{array}{c}\text { Vendas Médias } \\
\text { Esperadas dos } \\
\text { Projectos em } \\
\text { Estufas (contos) }\end{array}$ & $\begin{array}{c}\text { Vendas Médias } \\
\text { Esperadas Totais } \\
\text { (contos) }\end{array}$ & $\begin{array}{c}\text { Vendas Médias } \\
\text { Estufas / Vendas } \\
\text { Totais } \\
\text { (\%) }\end{array}$ \\
\hline Especialistas & 6433,67 & 6749,06 & 95,34 \\
\hline Diversificadores & 3516,82 & 5141,25 & 68,40 \\
\hline Minimalistas & 1082,18 & 6348,18 & 17,01 \\
\hline Todos os Investidores & 4439,62 & 6210,68 & 71,48 \\
\hline
\end{tabular}

No respeitante à estrutura da propriedade, é de referir que a área das explorações dos investidores minimalistas é em média o dobro da das outras categorias. Quanto à posse da terra, os diversificadores reflectem a situação observada para o caso geral (de 100 agricultores), sendo os minimalistas predominantemente proprietários da exploração onde 0 investimento se realiza, ao contrário do que acontece com os especialistas. 
Conforme já referimos em 3.1.a., os investidores recorrem em grande medida a projectistas para elaborarem os seus planos de melhoria. De salientar que os diversificadores são ligeiramente menos dependentes destes técnicos que os outros tipos de investidores e que, nas categorias de diversificador $\mathrm{e}$ minimalista, a intervenção do projectista é claramente diferente da que presta aos especialistas. Enquanto encontramos apenas um número muito reduzido de projectistas ligados aos projectos de empresários especializados na agricultura em estufas, na preparação de planos de melhoria para diversificadores e minimalistas, foram envolvidos muito mais projectistas, cada um responsável por apenas dois ou três planos, intervindo aparentemente de uma forma pontual e fortuita.

\subsection{Terceira tipologia: o grau de experiência empresarial}

A viabilidade dos investimentos em estufas pode ser também influenciada pelo grau e pelo tipo de experiência empresarial anterior do agricultor. Assim, decidimos, ao analisarmos os dados disponíveis, distinguir entre os agricultores que denominámos investidores principiantes, cujos investimentos em estufas representaram a sua primeira experiência empresarial, e os investidores experientes, os que já dispunham de alguma experiência empresarial, tanto no sector agrário - relacionada ou não com a agricultura de estufas - ou fora dele.

$\mathrm{Da}$ análise dos planos de melhoria concluímos que $70 \%$ dos agricultores observados se inserem no grupo dos principiantes e, consequentemente, 30\% na categoria de investidores experientes. A inclusão de determinado agricultor no grupo dos experientes foi realizada após um processo exaustivo, que teve como base os seguintes critérios?:

(1) $O$ investidor encontra-se registado na Direcção Regional da Agricultura como agricultor associado;

(2) Apresentação conjunta de um plano de melhoria por vários investidores em associação formal ou informal;

(3) O agricultor já submeteu anteriormente um plano de melhoria ao IFADAP;

(4) O investidor já recebeu um subsídio para a primeira instalação como Jovem Agricultor;

(5) O agricultor já comprovou formalmente ser a agricultura a sua actividade principal;

(6) Na secção sobre 'Aproveitamento da Exploração' do plano de melhoria, o investidor apresentou os dados respeitantes aos resultados financeiros da situação antes do projecto. 
Em oposição, os principiantes podem ser genericamente definidos como os investidores para os quais a actividade agrícola não era a actividade principal, com reduzida experiência em agricultura de estufas (e mesmo em gestão agrária), que nunca submeteram à aprovação qualquer plano de melhoria, nesta ou em qualquer outra área, mas que passariam a dedicar-se á agricultura como actividade principal se o plano de melhoria apresentado ao IFADAP fosse aprovado.

Com base nos critérios objectivos acima definidos, vamos seguidamente apresentar o perfil destes dois tipos de investidores.

A cronologia dos investimentos de ambos os tipos de investidores seguiu o padrão já referido no caso geral. No entanto, é interessante observar que, em termos relativos, os principiantes tiveram uma fase de arranque mais lenta $e$ menos sustentada que os experientes, apresentando um pico muito acentuado em 1994. Esta constatação pode ser em parte explicada pelo facto de os últimos terem já beneficiado de ajudas anteriores, ou devido à proliferação em 1994 de investimentos "oportunistas" dos agricultores acima denominados de minimalistas.

Destaque-se, neste ponto, que os principiantes se localizaram, de uma forma mais ou menos uniforme, no eixo Chaves-Vila Real-Lamego, ao passo que os experientes se situaram principalmente na área de Lamego (mais de 40\%) e, menos marcadamente, nos concelhos de Chaves e Vila Real (cerca de $33 \%$ e $27 \%$, respectivamente).

$\mathrm{O}$ investimento médio apresentado pelos principiantes foi em média o dobro do do outro grupo (cerca de 12000 e 6100 contos, respectivamente). Tendo em conta que o valor esperado das vendas é, no entanto, semelhante nos três tipos de investidores, conclui-se que a taxa de retorno bruta dos experientes é muito superior à dos principiantes $(58 \%$ e $28 \%$, respectivamente). Uma explicação mais concreta para esta constatação necessitaria de investigação empírica adicional ao nível da exploração. No entanto, ela parece sugerir que o grau de experiência do agricultor - tanto em termos da gestão da empresa como na previsão dos benefícios gerados por uma determinada iniciativa - desempenha um papel importante no sucesso ou insucesso do investimento, mesmo que as suas despesas sejam fortemente subsidiadas.

Paradoxalmente - ou pelo menos assim parece - quanto maior a dimensão do investimento, menor é a experiência empresarial prévia dos investidores envolvidos. Enquanto que cerca de um terço dos pequenos investidores são principiantes, cerca de $75 \%$ e $90 \%$, dos médios e grandes investidores respectivamente, não possuem experiência empresarial prévia, reflexo de uma forte presença de jovens agricultores, tanto na floricultura como em projectos mistos. 
Os agricultores experientes são predominantemente homens, em contraste com o grupo dos principiantes, onde os investidores femininos são tão numerosos como os masculinos. Aqueles são também mais idosos, com um grau de escolaridade inferior aos últimos e tendem a não arrendar terra para realizar o projecto. Por sua vez, a esmagadora maioria dos principiantes recorrem ao arrendamento.

$\mathrm{Na}$ categoria de investidores experientes o peso dos especialistas, diversificadores e minimalistas é semelhante, ao passo que no grupo de principiantes os especialistas (sobretudo em floricultura) predominam.

Finalmente, uma nota sobre o papel dos consultores privados. A contribuição dos projectistas na preparação dos planos de melhoria foi de grande relevância em ambas as categorias: no caso dos principiantes, em mais de $80 \%$ e no dos experientes em cerca de $60 \%$ das observações. Dada a estreita correspondência entre especialistas (em floricultura) e investidores principiantes, não é de estranhar que o número de consultores activos seja muito mais baixo neste caso do que no dos investidores experientes, uma vez que estes últimos possuem experiência empresarial anterior, agrícola ou não, e/ou já terão apresentado pelo menos um plano de melhoria. Esta conclusão leva à interessante questão de saber se o papel desempenhado pelos projectistas é principalmente o de complementar a actividade de extensão dos técnicos dos serviços públicos, ou de aproveitar - através do seu conhecimento especializado - da existência dos fundos para a agricultura em estufas.

\section{REFLEXÕES SOBRE OS PERFIS DOS INVESTIDORES}

No período analisado, a maioria dos investimentos foi de média dimensão (5 000 - 15000 contos), realizados por promotores com menos de 35 anos de idade, sendo a percentagem de mulheres quase igual à dos homens. Uma proporção significativa de projectos visou a concretização de uma estratégia de especialização em floricultura ou em horto-floricultura.

Os factores relacionados com o ambiente interno da empresa agrícola nomeadamente considerações tecnológicas e de escala - explicam a tendência dos investimentos para se concentrarem quantitativamente no escalão médio e geograficamente em determinados clusters no eixo Chaves - Vila Pouca de Aguiar - Vila Real - Lamego.

Naturalmente que o investimento subsidiado naquelas actividades obriga as empresas agrícolas a actuar numa fileira produtiva mais ampla, onde a concorrência é aguda e as relações de dependência entre fornecedor e cliente são fortes. Neste contexto, necessita de participar numa rede institucional de 
apoio e acompanhamento complexa, composta por empresas fornecedoras de equipamento e inputs, delegações de vários ministérios, instituições de crédito, centros de formação e consultores técnicos, cada um dos quais com competências, experiência, acesso à informação, interesses, poder económico e influências políticas diferentes.

Tipicamente, o processo de investimento foi iniciado em 1991-93 com investimentos mais modestos (até 5000 contos), feitos por promotores mais idosos (alguns deles não elegíveis para apoios a jovem agricultor), com níveis de instrução extremamente baixos e uma experiência empresarial que assentava mais no comércio que na agricultura. Possuidores de explorações com uma área agrícola relativamente elevada, estes investidores continuaram a apostar numa agricultura diversificada. Por esta razão, e apesar das limitadas dimensões do seu investimento, mais de metade apresentaram um projecto no qual a componente em agricultura em estufas tinha uma expressão mínima. Estes proponentes recorreram menos aos projectistas e, em particular, não utilizaram muito os projectistas mais activos.

Genericamente, os promotores mais jovens e com mais instrução optaram por maiores investimentos. Esta correlação levou-nos a questionar sobre a importância relativa das várias condicionantes da sua atitude perante ao risco. Será que a recente disponibilização de subsídios exerceu influência no comportamento dos investidores agrícolas, ou devemos atribuir maior importância ao alargamento das oportunidades da educação de uma geração de agricultores mais jovens?

O peso dos agricultores principiantes no grupo de pequenos investidores foi baixo, constituindo, contudo, a esmagadora maioria das categorias do médio e do grande investidor. Também, à medida que nos movemos de um extremo ao outro do contínuo especialistas - diversificadores - minimalistas, diminui a importância dos médios investidores, relativamente à dos pequenos e grandes. Por sua vez, os investidores principiantes (maioritariamente de média escala e virados para a floricultura) esperavam gerar três quartos do valor total de vendas, a partir das suas actividades ligadas às estufas; as previsões dos empresários mais experientes (principalmente diversificadores ou minimalistas) rondavam somente os $50 \%$.

Existe, actualmente, entre Chaves e Vila Pouca de Aguiar um cluster bem estabelecido de unidades produtoras de culturas em estufas, embora o eixo Vila Real - Lamego tivesse constituido o berço deste ramo de produção. Os investimentos iniciais foram concretizados por agricultores com uma experiência empresarial que, muitas vezes, ultrapassou a gestão de uma exploração familiar típica. Foi só após este primeiro impulso que se realizaram investimentos substanciais por parte dos empresários principiantes. Em termos relativos, o peso dos empresários experientes é maior na categoria dos minimalistas (mais de um terço), tendo uma expressão menor nos grupos de 
especialistas e diversificadores, onde predominam os principiantes $(78 \%$ e $70 \%$, respectivamente). Seria, no entanto, interessante investigar com mais profundidade esta associação aparente entre a experiência empresarial anterior (baseada numa agricultura virada para o mercado ou no trabalho assalariado por exemplo no estrangeiro) e o sucesso empresarial (ou seja, a viabilidade económica sustentável dos investimentos realizados).

Em termos gerais, independentemente do grau de especialização ou diversificação das suas explorações agrícolas, os proponentes recorreram bastante ao apoio de consultores privados na preparação dos seụs projectos e, quanto mais elevado o valor dos investimentos, mais frequente é o seu envolvimento: metade dos planos de pequenos investidores, três quartos dos médios e $83 \%$ dos grandes foram preparados por projectistas. Porém, fica por esclarecer se os agricultores que pretendem realizar grandes investimentos contactam projectistas, e/ou se estes últimos, com o objectivo de maximizar as suas comissões, procuram clientes exercendo alguma influência sobre a escala final do investimento realizado.

Quase metade dos planos de melhoria foram apresentados por mulheres. A única diferença entre o seu padrão de investimento e o dos promotores masculinos está no facto de elas serem relativamente mais numerosas no escalão inferior (até 5000 contos). Contudo, é prematuro interpretar este número tão elevado de mulheres promotoras de novos investimentos neste sub-sector, como indicação de um surto de empresarialismo feminino agrícola, embora a participação, cada vez maior de mulheres, directa ou indirecta, na criação de um tecido empresarial rural seja inegável. Em certos casos, a assinatura de um promotor feminino poderá apenas evidenciar a maximização de subsídios a obter pelo marido (ou, eventualmente, outro familiar). Para conclusões mais sólidas seria necessário estudar mais especificamente a autonomia relativa e a sustentabilidade de actividades empresariais das mulheres rurais, tendo em conta a natureza da sua participação na identificação e na concretização de uma estratégia familiar de (pluri-)emprego e (pluri-)rendimento.

Finalmente observa-se que um número limitado, mas significativo, de promotores de tipo minimalista apostaram, mais oportunisticamente que estrategicamente, na agricultura em estufas, pois devido à mudança nos critérios de eligibilidade para os subsídios ao investimento, tornou-se mais vantajoso incluir a instalação de estufas como componente marginal do plano de melhoria, a fim de assegurar que o projecto na sua totalidade possa gerar, pelo menos, a ocupação de uma unidade homem-trabalho. A maior parte de investimentos com estas características realizou-se no eixo Vila Real-Lamego. 


\section{IMPLICAÇÕES PARA FUTURA INVESTIGAÇÃO}

Os resultados obtidos e os dados qualitativos, recolhidos dos vários documentos fornecidos pelos promotores, permitiram identificar: os contornos sociais e empresariais de uma nova geração de investidores agrícolas no boom do investimento em agricultura em estufas; o papel "vanguardista" desempenhado pela floricultura; as especificidades do processo de investimento que levou à entrada de numerosos "principiantes" - jovens agricultores - no mercado e na fileira horto-florícola.

Sem questionarmos a validade das conclusões deste trabalho, naturalmente que os resultados alcançados têm de ser perspectivados à luz dos dados disponíveis e das técnicas e métodos utilizados. Existe, contudo, um conjunto de questões que deverão ser objecto de investigação, no futuro em especial as seguintes:

- Se o processo fosse condicionado mais pelo lado da procura (demand-led) que da oferta (supply-led), o papel dos actores envolvidos seria o mesmo? Por exemplo, para aprofundarmos esta questão é necessário avaliar empiricamente a influência dos principais actores na fileira flori-hortícola, quer particulares, quer empresariais e/ou institucionais, a montante e a jusante, na estruturação empresarial e territorial de novas iniciativas produtivas e na repartição final dos benefícios (Kirby et al, 1996).

- Será que os investimentos realizados foram simplesmente viáveis em termos técnico-financeiros ou também quantitativa e qualitativamente um contributo sustentável para alteração do tecido empresarial da área desfavorecida em que se inserem? Qual o seu impacte na produtividade, em especial na do trabalho? Qual o impacto deste tipo de instrumentos financeiros no volume de transações entre fornecedores de inputs agrícolas $\mathrm{e}$ os agricultores?

- Qual o impacte de variáveis como o nível de instrução na evolução deste componente específico do tecido empresarial da região de Trás-os-Montes e Alto Douro? A formação profissional tem proporcionado os efeitos desejados? (De Young, 1991).

- Que políticas deverão ser definidas neste sector? Será aconselhável apostar em empresas e empresários mais fortes (ou seja, os mais viáveis), ou em iniciativas que trarão efeitos mais positivos ao tecido empresarial em geral e à viabilidade socioeconómica local? (Panayiotopoulos e Gerry 1997).

Esperamos, futuramente, dar resposta a parte das questões aqui colocadas. 


\section{NOTAS}

${ }^{1}$ Os "técnicos-especialistas" consideravam o clima austero e o carácter montanhoso da região, o dificil acesso aos principais centros de consumo (de forma a permitir um escoamento regular da produção) e a falta de experiência dos agricultores como factores impeditivos ao desenvolvimento da agricultura em estufas em Trás-os-Montes e Alto Douro. No entanto, ao longo dos anos estas atitudes e prioridades foram-se modificando, permitindo que fossem criadas linhas de crédito para promover este tipo de agricultura.

${ }^{2}$ Os autores agradecem ao Director Geral do IFADAP, em Lisboa, por ter autorizado a consulta dos planos de melhoria e outra documentação de importância crucial para a realização deste trabalho. Agradecem ainda à Senhora Enga. Ana Moldão, da Delegação do IFADAP em Vila Real, todo o apoio prestado.

3 Desta forma, seria possível avaliar a importância relativa tanto na evolução empresarial, como no (in)sucesso do empreendimento, de variáveis tais como: o nível de ensino, formação técnica agrária, o papel de intermediários comerciais - inclusive o dos projectistas e consultores.

${ }^{4} \mathrm{~A}$ interpretação destes valores deve ser feita com precaução. Duas hipóteses se podem levantar na sua interpretação: (1) durante este período de 5 anos, o valor do investimento feito pelas mulheres poderá ser menor que o apresentado, e, portanto, ter sido sobreestimado na nossa análise. Na verdade pode acontecer que um seu familiar masculino (pai, marido, etc.) use a sua assinatura (pedido) para solicitar financiamento para projectos que pretende realizar e para os quais não preenche as devidas condições de elegibilidade; ou (2) reflecte um verdadeiro aparecimento da mulher como investidora e empresária.

${ }^{5}$ Ver também Quadro 9, seç̧ão 4, para mais informação.

${ }^{6}$ Calculado com base nos resultados de exploração previsionais ou seja, vendas totais previsionais menos custos totais incluindo o serviço de dívida. Foi ainda computado o peso destes resultados no montante total investido, expresso em percentagem. Estes cálculos pressupõem que os investidores inflacionaram o investimento e as vendas esperadas em cerca de $5-10 \%$.

${ }^{7} \mathrm{Na}$ clạsse dos médios investidores, a distribuição das observações é também uniforme.

${ }^{8}$ Respectivamente de 11230,9030 e 10833 contos para especialistas, diversificadores e minimalistas.

${ }^{9}$ Os critérios aqui mencionados são complementares; isto é, para um investidor ser considerado experiente, não é necessário que preencha todos eles se, com informação adicional retirada dos planos de melhoria e de documentação associada, pudermos detectar um grau mínimo de experiência anterior. 


\section{Anexo 1 \\ PLANOS DE MELHORIA: VARIÁVEIS ANALISADAS}

1. $\mathbf{N}^{\circ}$ do Plano de Melhoria.

2. Código do IFADAP relativo à localização do investimento.

3. Idade do proponente.

4. Proponente: sexo.

5. Localização (código postal) do investimento.

6. Estado civil e regime de propriedade do proponente.

7. Data de entrada do projecto (plano) de melhoria.

8. Projecto de melhoria individual ou não individual.

9. Autoria da elaboração do projecto (pelo proponente ou por um projectista).

10. Primeiro Plano de Melhoria ou Posterior.

11. Plano de Melhoria Submetido por um Jovem agricultor com capacidade profissional de 5 anos ou menos.

12. Subsídio à primeira instalação como Jovem Agricultor.

13. Subsídio à habitação própria do Jovem Agricultor.

14. Ajuda Suplementar ao Jovem Agricultor.

15. Tipo de agricultor (individual ou não individual).

16. Agricultor a título principal antes/depois do plano de melhoria.

17. Experiência profissional agrícola (anos).

18. Habilitação escolar agrícola.

19. Cursos de formação profissional de curta duração reconhecidos pelo Ministério da Agricultura.

20. Anos de escolaridade.

21. Contabilidade (tem; pretende ter; isento).

22. Exploração situada em região desfavorecida.

23. Forma exploração: Ha de Área por conta própria e área arrendada.

24. Possui outra exploração para além da considerada neste projecto?

25. Exploração de regadio/sequeiro.

26. $\mathrm{N}^{\circ}$ de ha de S.A.U. de regadio e sequeiro, superfície florestal e área inculta.

27. Renda Paga pelo terreno onde se realizará o investimento.

28. Máquinas e equipamentos da exploração (designação e características).

29. Plano de Melhoria Puro/Misto.

30. Investimento a realizar.

31. Vendas totais esperadas (após plano de melhoria).

32. Vendas esperadas provenientes das actividades: flores, vegetais, frutícolas (após plano de melhoria)

33. Valor das vendas esperadas de toda a produção após Plano de Melhoria. 
34. Valor das vendas esperadas da produção realizada em estufas após Plano de Melhoria.

35. Resultados.

36. Acréscimo de rendimentos (antes do plano de melhoria/após Plano de Melhoria).

37. Mão-de-obra familiar permanente (em dias/ano - antes do plano de melhoria).

38. Mão-de-obra familiar temporária (em dias/ano - antes do plano de melhoria).

39. Mão-de-obra familiar assalariada permanente (em dias/ano - antes do Plano de Melhoria).

40. Mão-de-obra familiar assalariada temporária (em dias/ano - antes do Plano de melhoria).

41. Mão-de-obra familiar permanente (em dias/ano - após o plano de melhoria).

42. Mão-de-obra familiar temporária (em dias/ano - após o plano de melhoria).

43. Mão-de-obra familiar assalariada permanente (em dias/ano - após o Plano de melhoria).

44. Mão-de-obra familiar assalariada temporária (em dias/ano - após o Plano de Melhoria).

45. Subsídio esperado à actividade da exploração. 


\section{Anexo 2}

PLANOS DE MELHORIA COM COMPONENTE DE AGRICULTURA EM ESTUFAS, POR CONCELHO, TRÁS-OS-MONTES E ALTO DOURO, 1987-95.

\begin{tabular}{|l|c|c|c|c|c|c|c|c|c|c|}
\hline \multicolumn{1}{|c|}{ Zona } & 1987 & 1988 & 1989 & 1990 & 1991 & 1992 & 1993 & 1994 & 1995 & Total \\
\hline Alfândega da Fé & & & & & & 2 & 1 & & & 3 \\
\hline Alijó & & & & & & 1 & & & & 1 \\
\hline Armamar & & & & & 1 & & 1 & 2 & & 4 \\
\hline Botícas & 1 & & & & & & & 2 & 1 & 4 \\
\hline Bragança & & 1 & 1 & & 2 & & & & & 4 \\
\hline Carrazeda de Ansiães & & & & & 1 & & & 2 & & 3 \\
\hline Chaves & & & 1 & 1 & 4 & 5 & 9 & 13 & 1 & 34 \\
\hline Lamego & & 1 & 2 & 2 & 3 & 1 & 3 & 2 & 3 & 17 \\
\hline Macedo de Cavaleiros & & 1 & & & 1 & & & 1 & & 3 \\
\hline Mesão Frio & & & 1 & & 1 & & & 1 & & 3 \\
\hline Mirandela & & & & & 1 & & & 5 & & 6 \\
\hline Moimenta da Beira & & & & & 1 & 1 & 2 & 3 & & 7 \\
\hline Montalegre & & 1 & & & & 1 & & 1 & & 3 \\
\hline Murça & & 1 & & & & & & 1 & 1 & 3 \\
\hline Peso da Régua & & & & 1 & 1 & & 1 & 1 & & 4 \\
\hline São João da Pesqueira & & & & & 1 & 1 & & & & 2 \\
\hline S.'ㅁ Marta de Penaguião & & & & & & & 1 & 1 & & 2 \\
\hline Tarouca & & & & & & 1 & & & & 1 \\
\hline Torre de Moncorvo & & & 1 & & & & & 1 & & 2 \\
\hline Valpaços & & & & & 1 & & 2 & 2 & 3 & 8 \\
\hline Vila Flor & & & & & & & 1 & & & 1 \\
\hline Vila Nova da Foz Côa & & & & & & & 1 & & & 1 \\
\hline Vila Pouca de Aguiar & & & & & 2 & 3 & & 3 & 3 & 11 \\
\hline Vila Real & 1 & & 2 & & & 1 & 1 & 5 & 2 & 12 \\
\hline Vinhais & & & & & & & & 2 & & 2 \\
\hline Total & 5 & 8 & 4 & 20 & 17 & 23 & 48 & 14 & 141 \\
\hline
\end{tabular}




\section{BIBLIOGRAFIA}

ALDONADO Ochoa, Ana Maria (1992), "El Comercio Mundial del Clavel: efecto del processo de globalización de la producción de flores y plantas ornamentales", Investigación Agrária (Economia), Vol 7, № 1, p. 95-120.

De YOUNG, A. (1991), "Economic Underdevelopment and its effect on Formal Schooling in Southern Appalachia", American Educational Research Journal, 28 (2), p. 297-315 .

IFADAP (1997), "Trás-os-Montes: projectos aprovados com investimento em estufas e abrigos, 1987 a 1996", Lisboa, Instituto de Financiamento de Apoio ao Desenvolvimento da Agricultura e Pescas.

KIRBY D. et al (1996), "A Comparative Study of an Emerging Form of Entepreneurship: technical consultants in Hungary, Poland and the UK", in Entrepreneurship, Theory \& Practice, London.

PANAYIOTOPOULOS, Prodromos e GERRY, Chris (1997), "Youth Enterprise Promotion in the Commonwealth Developing Countries: Learning from State-Sponsored Programmes", in Third World Planning Review, Vol 19, No 2, Maio, p. 209-227.

PEREIRA, Fernando (1996), Novas Dinâmicas de Diversificą̧ão da Agricultura Transmontana. Dissertação de Mestrado, UTAD, Vila Real (mimeog.). 